\title{
Impact of convection on thermographic analysis of silver based thermal joints
}

\author{
Krzysztof Fakub Stojek and Fan Felba \\ Faculty of Microsystem Electronics and Photonics, Wroclaw University of Science and Technology, Wroclaw, Poland \\ Johann Nicolics \\ TU Wien Institute of Sensor and Actuator Systems, Wien, Austria, and \\ Dominik Wotczyński \\ Wroclaw University of Science and Technology, Wroclaw, Poland
}

\begin{abstract}
Purpose - This paper aims to develop thermal analysis method of thermal joints characterization. The impact on convection on thermal resistance analysis with use thermography for silver-based thermal joints were investigated for non-metallized and metalized semiconductor surfaces. Heat transfer efficiency depends on thermal conductivity; radiation was used to perform thermographic analysis; the convection is energy loss, so its removing might improve measurements accuracy.

Design/methodology/approach - Investigation of thermal joints analysis method was focused on determination of convection impact on thermal resistance thermographic analysis method. Measuring samples placed in vacuum chamber with lowered pressure requires transparent window for infrared radiation that is used for thermographic analysis. Impact of infrared window and convection on temperature measurements and thermal resistance were referred.

Findings - The results showed that the silicon window allowed to perform thermal analysis through, and the convection was heat transfer mode which create $15 \%$ energy loss.

Originality/value - It is possible to measure thermal resistance for silver-based thermal joints with convection eliminated to improve measurements accuracy.
\end{abstract}

Keywords Thermography, Convection, Silver nanoparticles

Paper type Research paper

\section{Introduction}

Modern trends in electronic industry, mainly miniaturization with simultaneous faster operation speed of electronic devices are causing larger amount of heat generation than in the past. Heat dissipation becomes crucial, where both technology and used material will ensure high conductivity thermal joints with simultaneous acceptable mechanical strength. Typical joining materials, solders and thermally conductive adhesives are no longer sufficient, because of their limited thermal conductivity (Xiao, 2013; Göbl and Faltenbacher, 2010). The mechanism of heat removal is made by using high thermal conductive layer as a filler between surfaces of heat generating element (heat source) and a proper substrate (might be a heat spreader). Their role is to fill micro-sized gaps which leads to thermal resistance decrease of such joint and heat transfer efficiency improvement. Silver becomes interesting material for heat removing applications, thanks to its relatively high thermal conductivity. Compared with the solder reflow interconnection, pressure-assisted silver sintering, besides better electrical and thermal performance, has also the advantages, such as more uniform interconnecting layers, and

The current issue and full text archive of this journal is available on Emerald Insight at: https://www.emerald.com/insight/0954-0911.htm

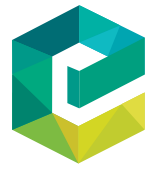

Soldering \& Surface Mount Technology 32/4 (2020) 241-246

Emerald Publishing Limited [ISSN 0954-0911] [DOI 10.1108/SSMT-11-2019-0040] higher reliability. That is why sintering process of nano- and microsized silver particles is increasingly used for thermal joint manufacturing in electronics (Siow, 2019). Parameters of joints depend on many technological and material factors, among which joined surfaces, temperature and time of sintering, external pressure and sintered material seem to be the most important (Felba, 2018). For this research, important technological parameters were selected experimentally (Stojek et al., 2017a, 2017b) including main sintering parameters - allowing to determine that the process is low temperature at low external pressure (below $250^{\circ} \mathrm{C}$ and less than $0.5 \mathrm{MPa}$ ). As mentioned before, there are given two main requirements for thermal joints: highest heat transfer efficiency as possible with simultaneous acceptable mechanical strength. The mechanical strength of the joints was not tested in this work, as previous studies have shown that this type of joints have sufficiently good mechanical

(C) Krzysztof Jakub Stojek, Jan Felba, Johann Nicolics and Dominik Wołczyński. Published by Emerald Publishing Limited. This article is published under the Creative Commons Attribution (CC BY 4.0) licence. Anyone may reproduce, distribute, translate and create derivative works of this article (for both commercial and non-commercial purposes), subject to full attribution to the original publication and authors. The full terms of this licence may be seen at http://creativecommons.org/licences/by/4.0/legalcode

Received 30 November 2019

Revised 6 March 2020

9 March 2020

30 March 2020

Accepted 7 April 2020 
parameters for applications in electronics (Stojek et al., 2017a, $2017 b$ ). Of course, there is no doubt that bulk silver is a highly conductive material ( $\sim 22 \mathrm{~W} / \mathrm{mK})$; however, sintered layer cannot be treated as bulk silver and its thermal conductivity has to be measured. Usually, this value is estimated on the base of Wiedemann-Franz law (Welker et al., 2015; Lu et al., 2007; Kähler et al., 2011), calculated by density, specific heat and thermal diffusivity measurement (Bai, 2005; Wang et al., 2013; Zhang and $\mathrm{Lu}, 2002$ ) or estimated by porosity evaluation ( $\mathrm{Fu}$ et al., 2014). We propose the direct measurement by using the thermography method. Their main features, such as contactless, repeatable, accurate, relatively fast and cheap determined the need of use this method. By measuring the source and heat receiver temperatures, it is possible to calculate the thermal resistance of the joint. Unfortunately, the measured heat balance is disturbed by radiation and convection phenomena. While at relatively low operating temperatures of electronic systems, it is justified to omit the phenomenon of radiation in ambient atmosphere when convection occurs. The purpose of this work is to assess the impact of this phenomenon on the accuracy of the measurement method used.

\section{Samples}

Heat sources (controllable silicon resistor) and heat receivers in research were made by $3000 \mu \mathrm{m}$ thick bare-die silicon with

Figure 1 Structures for thermal analysis of sintered silver layer

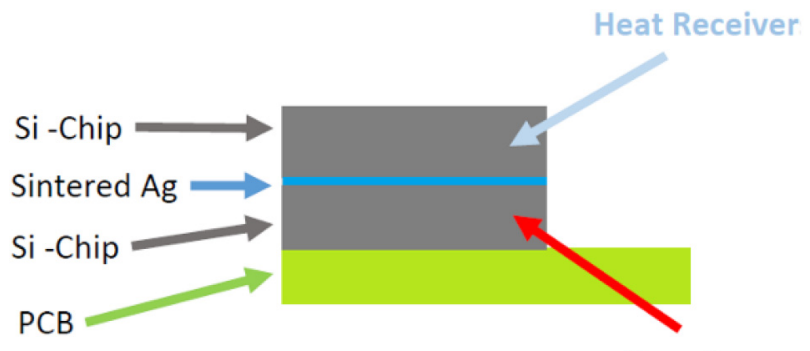

Heat Source dimensions of $5 \times 5 \mathrm{~mm}$. Both silicon parts are joined (Figure 1). The paste for sintering had $95 \mathrm{Wt} . \%$ of silver particles $(60: 40$ nano- to micro-sized flakes silver particles ratio) and $5 \mathrm{Wt} . \%$ of epoxy resin. Silver nanoparticles had average size $70 \mathrm{~nm}$ and micro-sized flakes about $15 \mu \mathrm{m}$. Addition of epoxy resin was allowed to manufacture thermal joints for non-metallized surfaces. The sintering process was done in $60 \mathrm{~min}$ in $230^{\circ} \mathrm{C} \mathrm{(+}$ $54 \mathrm{~min}$ of heating with ratio $\left.4^{\circ} \mathrm{C} / \mathrm{min}\right)$. The pressure assistance was present at level of $0.5 \mathrm{MPa}$.

\section{Basic temperature measurement setup}

Electrical power was supplied via printed circuit board, where interconnection was done by electrically conductive adhesive. Supplied power was transformed to heat in heat source and was transferred to heat receiver and the temperatures on source $\left(T_{S}\right)$ and receiver $\left(T_{R}\right)$ surfaces were measured simultaneously by the infrared (IR) camera (Figure 2) and presented configuration minimizes measurement errors (Stojek et al., 2017a, 2017b). Thermographic software tool "area" was used in analysis, where temperatures on source $\left(T_{S}\right)$ and receiver $\left(T_{R}\right)$ were average values for selected area. To ensure accurate temperature measurements, surfaces were covered by layer with known emissivity (0.98). Temperature measurements were performed in steady-state condition which needs to be considered as stabilized conditions, where conduction, radiation and convection got stable. Voltage (U) and current (I) measurements as an electrical power were done by Fluke 8,848 A multimeters. Obtaining the temperatures $T_{S}$ and $T_{R}$ and electrical power (U-voltage and I-current) allows us to calculate thermal resistance $\mathrm{R}_{\mathrm{TH}}$ with the formula:

$$
R_{T H}=\frac{\Delta T}{P}=\frac{T_{S}-T_{R}}{U \cdot I}
$$

which corresponds to source and receiver temperature difference in relation to supplied electrical power - Figure 2.

Temperature measurements values with using thermographic Flir A40m camera are performed with $\pm 2{ }^{\circ} \mathrm{C}$ or $\pm 2 \%$ accuracy,

Figure 2 Thermal resistance measurements schematic setup

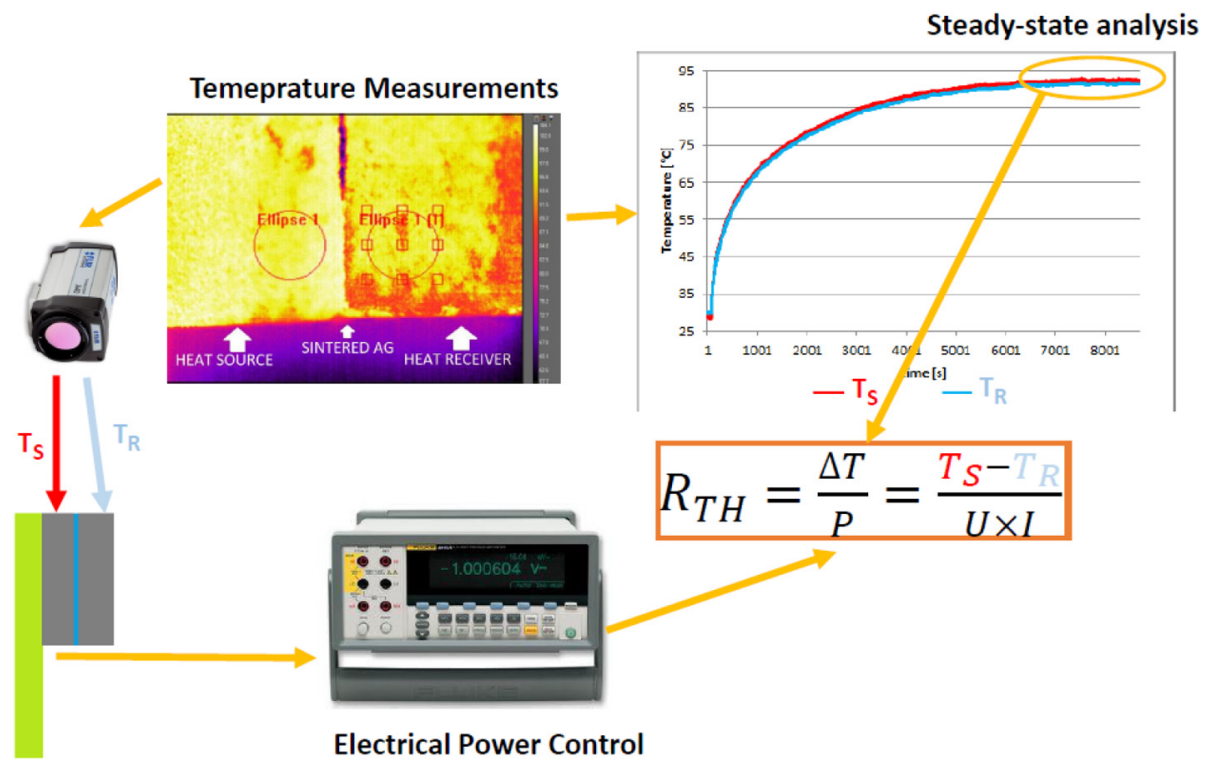


but thermal sensitivity at level $0.08^{\circ} \mathrm{C}$ at $30^{\circ} \mathrm{C}$. It means that temperature value measurements had an error, but lowest distinguishable difference are at level lower than $0.1^{\circ} \mathrm{C}$, so the temperature difference values are measured with high accuracy. External optic was used within measurements, where its impact was calibrated automatically by system.

\section{Principle for convection impact on thermal analysis estimation}

Basic measurements treated as a reference were made in atmospheric conditions - Figure 3(a) - AIR. In such measurements, configuration conduction corresponds to heat transfer through thermal joints, radiation corresponds to IR camera measurements, but convection causes an energy loss consumed by heating of surrounding air. In such manner, putting samples to vacuum chamber to remove the air was proposed. Nevertheless, putting IR camera to vacuum chamber was not possible, because its operation was not adjusted for lowered pressure condition. The vacuum chamber needs to be hermetic, and measurements are possible only through IR window, which is transparent for infrared radiation characteristic of the camera used (from 7.5 to $13 \mu \mathrm{m}$ ).

The configuration necessary to assess the transparency of the silicone window for measured temperatures (with atmospheric pressure inside the chamber) is shown in the Figure 3(b) - AIR,

Figure 3 Three configuration of thermal analysis measurements

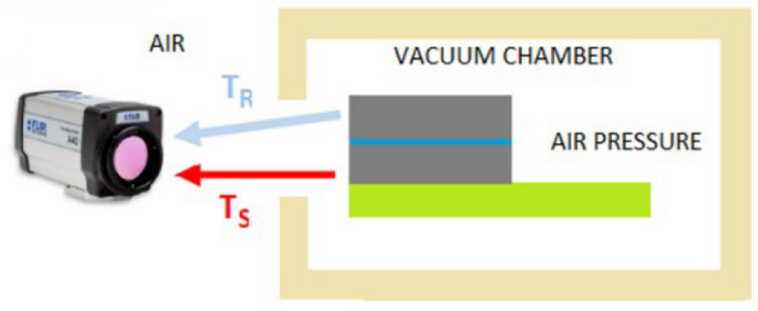

(a)

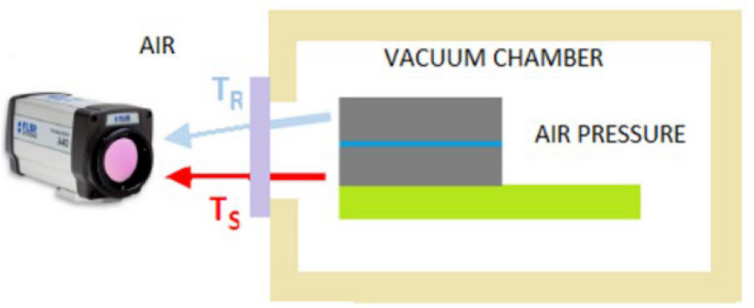

(b)

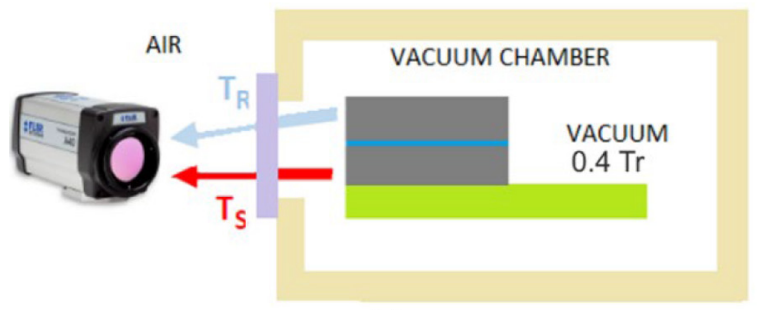

(c)

Notes: (a) - via air atmosphere; (b) - via silicon IR window in air, (c) - via silicon IR window in vacuum
IR WINDOW. Figure 3(c) - VACUUM, IR WINDOW - is a target configuration, which allows to assess of convection impact on thermal resistance analysis. Thermal measurements were also calibrated for ambient temperature, relative humidity and distance between object and camera. Using external optics allows to measure radiation by detector from area of $45 \times$ $47 \mu \mathrm{m}$.

\section{Temperature, power measurements and thermal resistance analysis results}

Within the research three samples were investigated. Source ( $\mathrm{Ts}$ ) and receiver $(\mathrm{Tr})$ temperatures measurements were done five times for each sample in each condition to perform statistical analysis. Their value were measured and calculated temperature differences ( $\mathrm{Ts}-\mathrm{Tr}$ ). The main values are presented in Figures 4 and 5, respectively. Simultaneously power measurements were done, and their mean values were calculated (Figure 6).

Adding IR window causes lowering of source and receiver temperatures. Lowering the pressure (vacuum conditions) causes increasing these temperature values in ratio to measurements in air atmosphere through IR window.

It is clear, that adding IR window to the optical path cause temperature difference increasing. On the other hand, for measurements through IR window, temperature difference

Figure 4 Mean source and receiver temperatures in air, air through IR window and in vacuum through IR window conditions

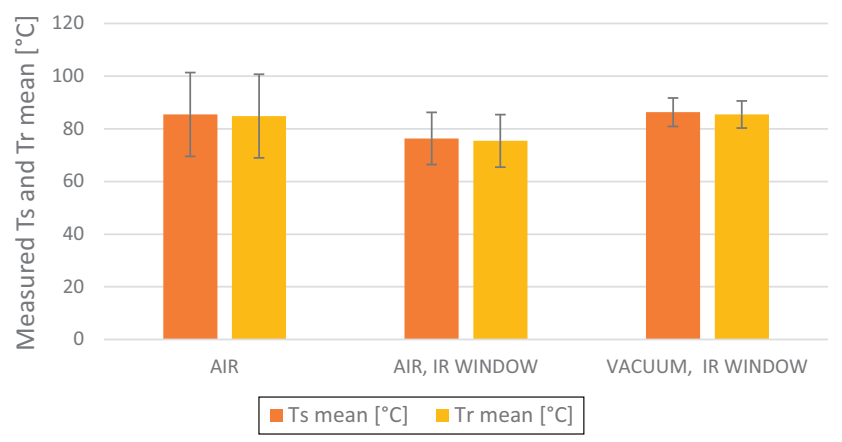

Figure 5 Mean source and receiver temperature differences in air, air through IR window and in vacuum through IR window conditions

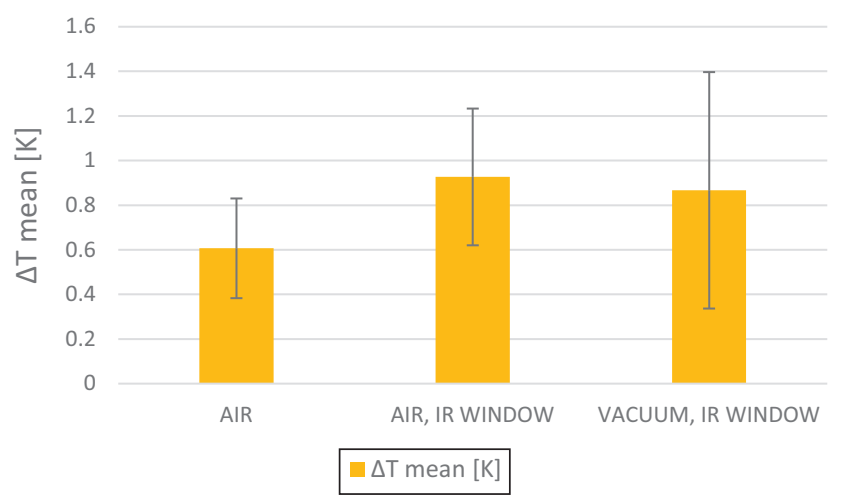


Figure 6 Mean power received to the samples in air, air through IR window and in vacuum through IR window conditions

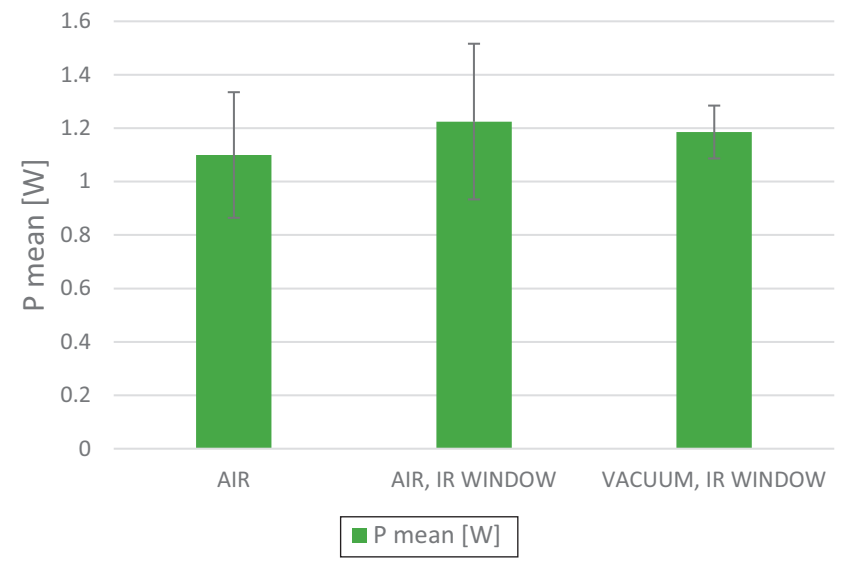

decreases with pressure lowering. Temperature value measurements were distorted by IR window absorption. Source and receiver temperature differences were calculated directly with respecting achieved values - there was no compensation for source and receiver temperature values.

Mean electrical power was the highest for measurements through IR window in air pressure conditions. It is important to underline that received electrical power was not equal within research (Figure 7).

Lowest thermal resistance was obtained for measurements in air without IR window and the highest for air pressure through IR windows. Measuring in vacuum conditions through IR window caused lowering of thermal resistance in relation to measurements in air conditions and through IR window also.

\section{IR window and convection impact on thermal resistance analysis}

Related thermal resistance calculations allowed us to determine the impact of IR window and pressure lowering impact on thermal resistance (Figure 8). With calculating the relation of thermal resistance in air pressure through IR window (Rth_AIR, IR WINDOW) to thermal resistance in air pressure without IR window (Rth_AIR) we were able to determine quantitatively their impact on results. In such

Figure 7 Mean thermal resistance in air, air through IR window and in vacuum through IR window conditions

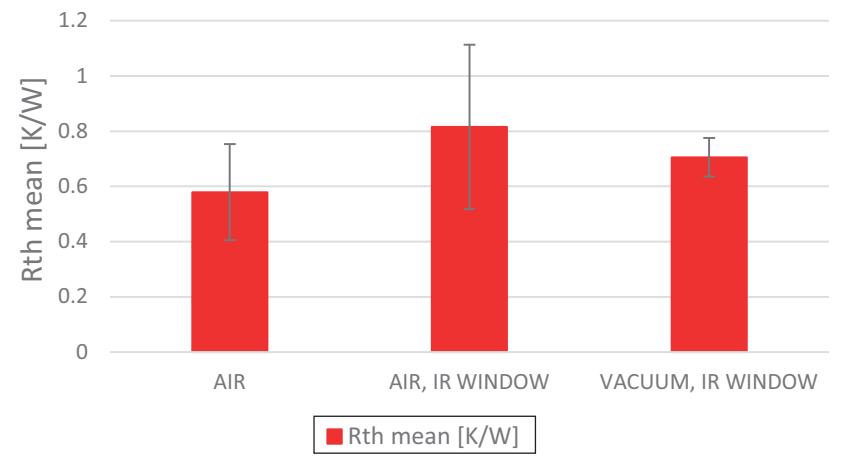

Figure 8 Related thermal resistance results affection by IR window and convection

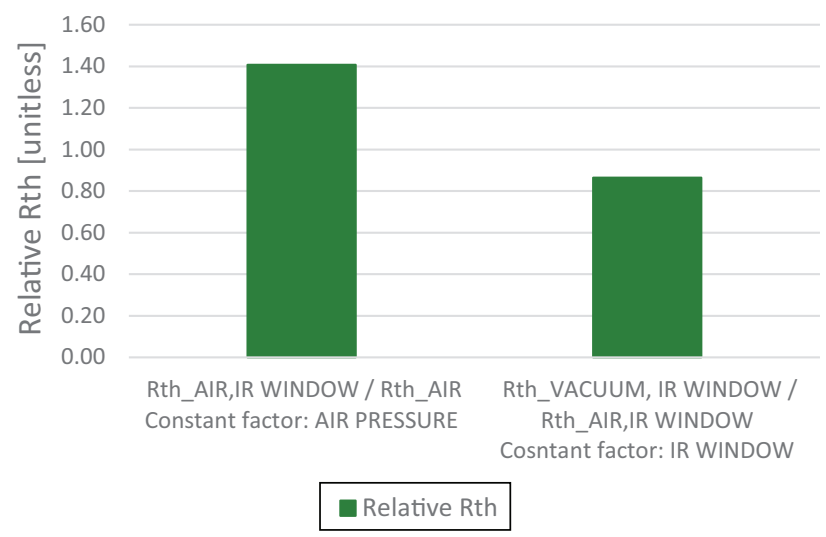

case the air atmosphere was constant factor and the IR window was one and only variable. Similar calculations were done for relation of thermal resistance in vacuum (Rth_VACUUM, IR WINDOW) to thermal resistance in air conditions through IR window (Rth_AIR, IR WINDOW), where IR window was constant factor, and pressure was one and only variable.

Adding IR window to optical path caused thermal resistance improvement for about $41 \%$ and convection (vacuum conditions) caused lowering of thermal resistance in about $15 \%$.

\section{Infrared window calibration}

In two previous chapters, research approach is based on analysis for direct measurements of source and receiver temperature difference. But still there is present absorption in IR window and thermal signal distortion (lowering). Silicon three-inched die was used as an IR window. To estimate source and receiver real values for measurements through this IR window, calibration was performed. Its impact measurements based on analysis in air atmosphere and were performed in steady-state conditions. At the beginning, the temperature of the source was stabilized in given electrical power points (I and $\mathrm{U})$, and source temperature was measured without IR window. In next step, the similar concept was used, but during these measurements the silicon IR window was placed in the optical path and then again steady-state analysis was done with the same electrical power supply (Figure 9).

Given results were fitted with linear function and given formulas for setup with $\left(y_{1}\right)$ and without $\left(y_{2}\right)$ IR silicon window were obtained in form, respectively:

$$
\left\{\begin{array}{l}
y_{1}=9.5 \cdot x+23 \\
y_{2}=5.5 \cdot x+25
\end{array}\right.
$$

Another step was to calculate the $y_{1}$, where $y_{1}$ is calculated temperature real value estimation for measurements done through silicon IR window. The temperature value were lowered because of such window transmission lower than $100 \%$ : 
Figure 9 Results of temperature measurements for setup with and without IR silicon window as a function of supplied power

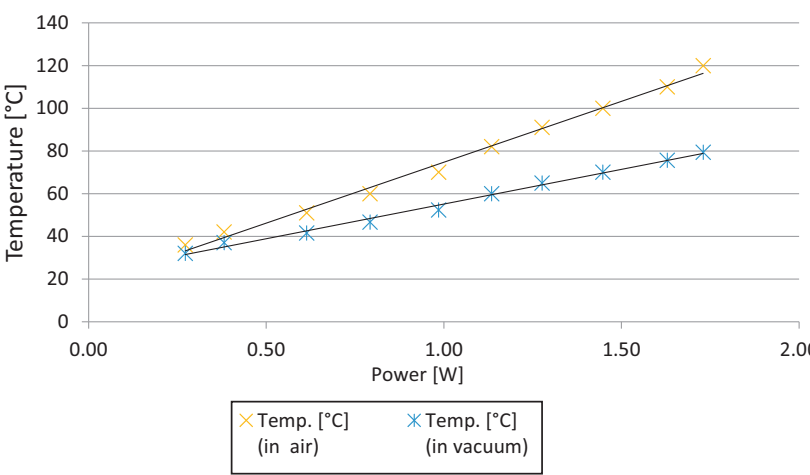

$$
y_{1}=9.5 \cdot\left(\frac{y_{2}-25}{5.5}\right)+23
$$

In such manner, every temperature measurement through IR window was estimated for real value (analysis in air and vacuum conditions) of direct (measured) and calibrated (calculated) mean temperature (Figure 10).

The results confirmed that using silicon IR window affects temperature measurements on about $40 \%$.

\section{X-ray inspection}

It is unclear what factors caused the increase in joint thermal resistance after surface metallization. Theoretically, this can be caused by adding to a chain of thermal resistances of a joint additional thermal resistances of metal layers and thermal contact resistance between layers and substrate (Felba, 2011). But the observed differences can also be the result of defects in the sintered layers. In fact, in X-ray images (Figure 11) defects

Figure 10 Source and receiver measured and calibrated mean temperatures

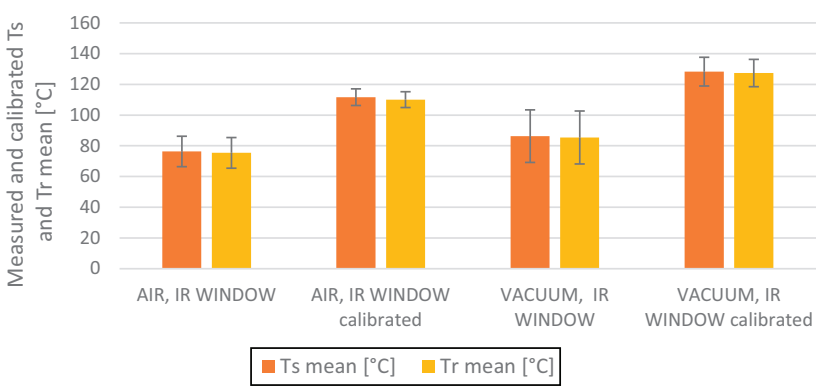

Figure 11 X-ray inspection of measured joints

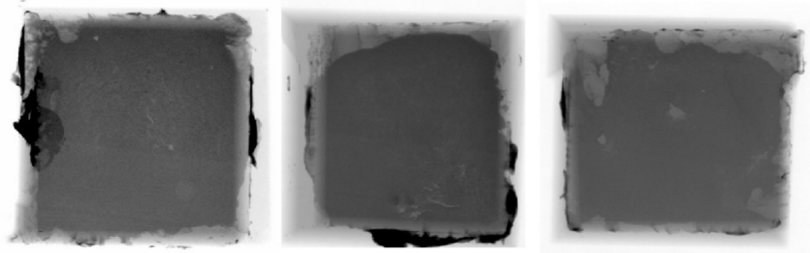

are clearly visible - mostly in form of void spaces (brighter areas) and it seems that the surface of these voids is larger in the case of metallized surfaces. This would explain the higher $\mathrm{R}_{\mathrm{TH}}$ value in these samples.

\section{Conclusions}

The convection impact on thermographic thermal resistance analysis reached about $15 \%$. Convection removal was done by putting samples in vacuum chamber in lowered pressure circumstances. Silicon IR window impact on thermal analysis were discussed and its impact on method was calibrated. Thermal resistance increased with using silicon IR window for measurements in air conditions and in lowered pressure. X-ray inspection showed the defects in layers but required further research.

\section{References}

Bai, G. (2005), "Low-temperature sintering of nanoscale silver paste for semiconductor device interconnection", $\mathrm{PhD}$ dissertation, Virginia Tech, Blacksburg, VA.

Felba, J. (2018), "Technological aspects of silver particle sintering for electronic packaging", Circuit World, Vol. 44 No. 1, pp. 2-15.

Felba, J. (2011), "Thermally conductive adhesives in electronics", in Alam, M.O. and Bailey, C. (Eds), Advanced Adhesives in Electronics: materials, Properties and Applications, Woodhead Publishing, pp. 15-52.

Fu, S., Mei, Y., Lu, G.-Q., Li, X., Chen, G. and Chen, X. (2014), "Pressureless sintering of nanosilver paste at low temperature to join large area $(\geq 100 \mathrm{~mm} 2)$ power chips for electronic packaging", Materials Letters, Vol. 128, pp. 42-45.

Göbl, C. and Faltenbacher, J. (2010), "Low temperature sinter technology; die attachment for power electronic application", 6th International Conference on Integrated Power Electronics System (CIPS), Nuremberg.

Kähler, J., Heuck, N., Palm, G., Stranz, A., Waag, A. and Peiner, E. (2011), "Low-pressure sintering of silver microand nanoparticles for a high temperature stable pick \& place die attach", 18th European Microelectronics and Packaging Conference, Brighton.

Lu, G.Q., Calata, J.N., Lei, G.Y. and Chen, X. (2007), "Lowtemperature and pressureless sintering technology for highperformance and high-temperature interconnection of semiconductor devices", International Conference on Thermal, Mechanical and Multi-Physics Simulation Experiments in Microelectronics and Micro-Systems, EuroSime.

Siow, K.S. (2019), Die-Attach Materials for High Temperature Applications in Microelectronics, Packaging Materials, Processes, Equipment, and Reliability, Springer .

Stojek, K., Felba, J., Fałat, T. and Mościcki, A. (2017a), "Different aspects of non-metalized silicon dies joining with using low temperature and low pressure sintered silver nanoparticles", 40th International Spring Seminar on Electronics Technology, Sofia .

Stojek, K., Felba, J., Fałat, T., Kiliszkiewicz, M. and Mościcki, A. (2017b), "The materials and technology parameters influenced on the mechanical properties of low temperature 
sintered silver joints", 21st European Microelectronics and Packaging Conference (EMPC) E Exhibition, Warsaw.

Wang, S., Li, M., Ji, H. and Wang, C. (2013), "Rapid pressureless low-temperature sintering of Ag nanoparticles for high-power density electronic packaging", Scripta Materialia, Vol. 69 Nos 11/12, pp. 789-792.

Welker, T., Müller, J., Krämer, F. and Wiese, S. (2015), "Electrical, thermal and mechanical characterization of low temperature, pressure-less sintered silver bond interfaces", European Microelectronics Packaging Conference, Friedrichshafen.

Xiao, K. (2013), "A diffusion-viscous analysis and experimental verification of the drying behavior in nanosilver-enabled low-temperature joining technique", Dissertation for Doctor of Philosophy, the Virginia Polytechnic, Institute and State University, Blacksburg, VA.
Zhang, Z. and Lu, G.Q. (2002), "Pressure-assisted lowtemperature sintering of silver paste as an alternative dieattach solution to solder reflow", IEEE Transactions on Electronics Packaging Manufacturing, Vol. 25 No. 4, pp. 279-283.

\section{Further reading}

Stojek, K., Nowak, D., Felba, J., Mościcki, A., Fałat, T. and Surmiak, A. (2018), "Heat transfer efficiency measurements with using thermography for low-temperature and lowpressure sintered silver joints", 7th Electronic SystemIntegration Technology Conference (ESTC), Dresden.

\section{Corresponding author}

Krzysztof Jakub Stojek can be contacted at: krzysztof. stojek@pwr.edu.pl 